\title{
Correlation for Predicting Heat Transfer Characteristics of A Helical Oscillating Heat Pipe (HOHP) at Normal Operating Conditions
}

\author{
Amorn Donmuang and Teerapat Chompookham*
}

\author{
Heat Pipe and Thermal Tools Design Research Unit (HTDR), Department of Mechanical Engineering, Faculty of Engineering, \\ Mahasarakham University, Khamriang, Kantarawichai, Maha Sarakham 44150, Thailand.
}

\begin{abstract}
The helical oscillating heat pipe (HOHP) is a high heat transfer heat exchanger with high flexibility in its installation and can therefore be used in a wide variety of applications. In this study, the effect of various parameters on the heat transfer rates of HOHP were used to establish a correlation equation for use in the heat flux prediction, the dimensionless parameters studied were $\rho_{v} / \rho_{l}, \mathrm{Bo}, \mathrm{Nu}$, $\mathrm{We}, \mathrm{Ja}, \mathrm{Pr}, \mathrm{Fr}, \mathrm{Co}, \mathrm{Ga}, \mathrm{Bi}, \mathrm{Wo}, \mathrm{Oh}$, and $\mathrm{Ku}$. Experiments were conducted to find out their effects on the heat transfer rates of copper HOHP with internal diameters were $2.03,3.5$, and $4.5 \mathrm{~mm}$. The lengths of evaporator and condenser sections were equal at 1500,2000 , and $2500 \mathrm{~mm}$. The pitch coils were 10, 15, and $20 \mathrm{~mm}$. The working fluids used were R134a, ethanol, and water with the filling ratios were $30 \%, 50 \%$, and $80 \%$ of the total internal volume. The temperature of evaporator section were varied between 60,70 , and $80^{\circ} \mathrm{C}$ within normal operating conditions in a vertical position. The results of the experiment showed that the internal diameter, lengths of evaporator/condenser sections, pitch coil, type of working fluid, filling ratio and temperature of evaporator section affected the heat transfer rates of the HOHP. The results of dimensionless parameters can establish the correlation equation to predict the heat flux for the HOHP as shown in this paper. In addition, the results of this research can be applied in the designing and construction of HOHP heat exchangers.
\end{abstract}

Keywords: Correlation, Heat transfer characteristics, Helical oscillating heat pipe, Heat exchanger, Dimensionless

Article History: Received: $13^{\text {th }}$ Oct 2020; Revised: $15^{\text {th }}$ Nov 2020; Accepted: $20^{\text {th }}$ Nov 2020; Available online: $23^{\text {rd }}$ Nov 2020

How to Cite This Article: Donmuang, A. and Chompookham, T. (2021) Correlation for Predicting Heat Transfer Characteristics of a Helical Oscillating Heat Pipe (HOHP) at Normal Operating Conditions. Int. Journal of Renewable Energy Development, 10(2), 171-182 https://doi.org/10.14710/ijred.2021.33671

\section{Introduction}

Heat exchangers are one of the most important devices in industrial applications. In particular shell and tube heat exchangers are used under very diverse operating conditions (Hoseinzadeh and Heyns 2020). Experimental and numerical analysis of their thermal performance importance have been investigated by (Hoseinzadeh et al 2018; Hoseinzadeh et al 2019; Hoseinzadeh et al 2020). Heat pipe is a type of heat exchanger that can transfer heat without external energy. It works by heat transferring from the latent heat of the working fluid inside the pipe, which evaporates when receiving heat from the heat source and then transfers the heat to the desired heat transfer material such as water or air and then condenses to return to the evaporator again. Because the latent heat of the vaporization of the working fluid is very high, it can transfer heat from one end to another with a slight temperature difference. In general, heat pipes consist of three sections are an evaporator section, an adiabatic section, and a condenser section. Heat pipes can be divided into two major types namely the conventional heat pipe, also known as the thermosyphon and special heat pipes which are many types such as oscillating heat pipes. (Akachi et al 1996) are described as the phenomenon they observed as a self-excited oscillating heat pipe (OHP) as the OHPs are passive two-stage heat transfer devices that do not require a mechanical pump for heat transfer. The main advantages of OHPs are their fast-thermal response, high heat transfer performance, compact size and very simple construction. However, the downside to OHPs are that they are unable to successfully operate at any orientation and their working principle has not been clearly explained. (Cheng and Ma 2011) studied and developed a mathematical model predicting the oscillating motion in an oscillating heat pipe. The model considers the system's multi-degree oscillation of vapor bubbles and liquid plugs. Including the effects of filling ratio, operating temperature, gravitational force, and the temperature difference between the evaporator and condenser. This gives a better understanding of heat transfer mechanisms occurring in the oscillating heat pipe. (Mameli et al 2012) studied pulsating heat pipe good agreement between numerical results and experimental

\footnotetext{
* Corresponding author: teerapat.c@msu.ac.th
} 
data coming from a single-loop PHP operating with ethanol was shown as using a single tuning parameter, which is the liquid film thickness around a vapor slug. (Karimi and Culham 2004) have presented OHPs may operate as an interconnected array of two-phase thermosyphons. (Maesawa et al. 1996) studied the heat transfer of closed-end oscillating heat pipe (CEOHP) occurring because of self-exciting oscillation of the working fluid. As a criterion to find the maximum inner diameter of a CEOHP it was assumed that where the vapor bubble is formed alternated with the liquid plug within the tube depending on the properties of the working fluid. (Katpradit et al. 2005) studied the heat transfer characteristics at critical state of a CEOHP. The presented parameters studied were: the section lengths, working fluid and the dimensionless parameters of heat transfer characteristics at critical state. The working fluids used were R123, ethanol, and water with a filling ratio of $50 \%$ of total volume of the tube. The CEOHPs were set to operate at both vertical and horizontal orientations with the working temperature maintained at $60^{\circ} \mathrm{C}$. They found that the critical heat flux decreased as the section length increased, but increased with an increase in the latent heat of vaporization of the working fluid. (Rittidech and Phalasin 2005) studied the heat transfer characteristics of a CEOHP depending on a number of parameters. The CEOHPs used employed a copper tube with inner diameters of $0.66,1.09$, and $2.03 \mathrm{~mm}$. The lengths of the evaporator, adiabatic, and condenser sections were equal and changed to 50, 100, and $150 \mathrm{~mm}$. R141b was used as the working fluid with filling ratio of $50 \%$ by total volume. The number of meandering turns used were 10, 20, and 40. The evaporator section was heated by hot water and the condenser section was cooled by distilled water. The experimental inclination angles were $0,20,40,60,80$, and 90 degrees from the horizontal plane. The controlled temperature at the adiabatic section was $50^{\circ} \mathrm{C}$. They showed that the heat flux decreased with an increase in the number of turns and decreased with an increase in aspect ratio. The heat flux also increased with an increase in inner diameter. They presented the fact that a correlation for predicting the heat transfer rate at vertical position can be established. (Charoensawan and Terdtoon 2008) experimentally investigated the thermal performance of a horizontal closed-loop oscillating heat pipe (HCLOHP) at normal operating conditions. They found out from all the experimental results that the operation start-up of a HCLOHP depended on the evaporator temperature that is related to the number of turns. The critical number of turns depends on the evaporator temperature and the inner diameter of the tube. (Shafii et al. 2010) have demonstrated to investigate these parameters first a closed-loop pulsating heat pipe (CLPHP) was designed and manufactured. A power-law correlation based on dimensionless parameters was established to predict their input heat flux. They compared the experimental data and the root mean square deviation of the correlation prediction was $19.7 \%$, and $88.6 \%$ of the deviations were within $30 \%$. The oscillating heat pipe can be classified into four types as shown in Fig. 1. The first type is the closed-end oscillating heat pipe (CEOHP) in Fig. 1(a), which is closed at both ends. Next is a closed-loop oscillating heat pipe (CLOHP) in Fig. 1(b), which is connected at both ends of the tube to form a closed loop.

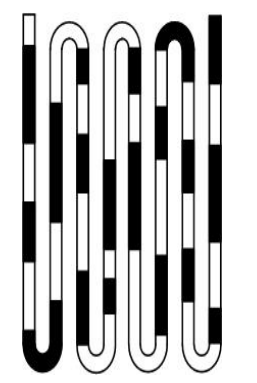

(a)

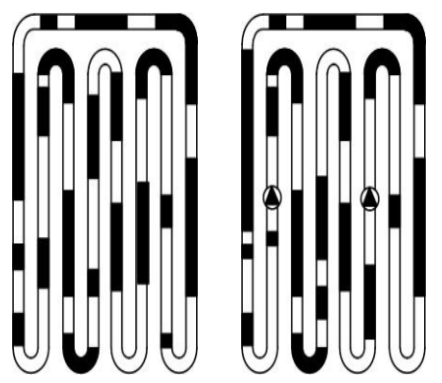

(c)

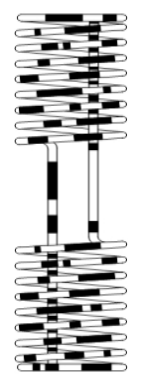

(d)
Fig. 1 Types of oscillating heat pipe (OHPs): (a) CEOHP, (b) CLOHP, (c) CLOHP/CV, and (d) HOHP

Next is a closed-loop oscillating heat pipe with a check valve (CLOHP/CV) in Fig. 1(c), which makes the working fluid move in a specific direction (Rittidech et al. 2003). The last type of OHP is helical oscillating heat pipe (HOHP) in Fig. 1(d), which is an application based on a heat pipe by designing the evaporator and condenser section to a tube bent into a helical shape to increase the heat transfer limit of the conventional heat pipe (Donmuang et al. 2014). The HOHP is a new type of heat pipe aiming at improving the evaporator and the condenser sections using helical coiled pipes. The heat transfer characteristics and the flow patterns in the small tube diameter of looped heat pipes were studied. The flow behaviors and complicated phenomena of flow patterns have not been covered nor specified (Yi et al. 2003). (Sriudom et al. 2014) studied the flow pattern behavior of a HOHP and the complicated phenomena of flow patterns were not covered or specified. They found four internal flow patterns namely bubble flow, slug flow, annular flow, and stratified wavy flow. The flow patterns of each working fluid were different. Afterward, (Siriwan et al. 2017) studied the heat transfer predictions for helical oscillating heat pipe heat exchanger in transient condition. They found that the transient heat transfer profiles of the HOHP from the numerical model were successfully compared with the results from the experimental data which utilizes the concept of heat transfer increments in the HOHP during transient operation. The applications of OHP were studied in the CLOHP/CV heat exchanger for preheating glycerin oil in Chinese black syrup boiling process, the CLOHP/CV heat exchanger was made from copper tube with an inner diameter of $4.68 \mathrm{~mm}$. Water was used as working fluid with $80 \%$ of total volume, the heat sources at high temperature from stove, the heat sink to transfer heat in glycerin oil tank. They found out the boiling process time of glycerin oil preheated by CLOHP/CV heat exchanger was less than liquefied petroleum gas boiling process (Donmuang et al. 2008). This feature makes the use of heat pipes desirable by many researchers: (Zhao et al. 2016, Tiari et al. 2015, Tiari et al. 2016, Mahdavi et al. 2018) and electronic cooling by many researchers: (Hassan and Harmand 2013, Adami and Yimer 1990, Peterson 1988, Mozumder et al. 2011). Heat pipes which use nanofluids as working fluid are one of the most preferred heat transfer ways because of their rapid effectiveness (Aydin et al. 2020: Hoseinzadeh et al 2017). Their applications are such as heat recovery in HVAC systems (Jouhara and Meskimmon 2018), waste heat recovery 
(Jouhara et al. 2017), temperature control of electronic devices (Zhu and Yu 2016), and solar collector (Rittidech et al. 2009). Heat exchangers can also be used in drying processes when appropriate temperature and relative humidity effects on the material are known. (Sasongko et al. 2020) studied the effects of drying temperature and relative humidity on the quality of dried onion slice. They found that the optimization using response surface method revealed that the optimum conditions of onion slice drying were achieved at $49.6^{\circ} \mathrm{C}$ and at a relative humidity of $0.65 \%$.

From the literature review, many correlation equations for oscillating heat pipes have been established, but there has not been a research which has established a correlation equation for HOHP. Therefore, the objective of this research is to experimentally investigate the effects of inner diameter, working fluid, condenser and evaporator section lengths, coil pitch and dimensionless parameters on thermal performance in HOHP. In concluding, twelve dimensionless correlations equation were proposed for predicting the heat flux of the HOHP and a comparison between the heat flux of experimental result and the heat flux of prediction were done.

\section{Experimental apparatus and procedure}

\subsection{The helical oscillating heat pipe (HOHP) set up}

OHP operation depends on alternating the formation of the vapor bubbles and liquid slugs of the working fluid in the vacuum pressure, the critical diameter defined by the axial vapor pressure must be greater than the transverse vapor pressure by using Eq. (1) (Maezawa et al. 1996).

$D_{i} \leq 2 \sqrt{\frac{\sigma}{\rho_{l g} g}}$

where:

- $D_{i}$ is the inner diameter (mm)

- $\sigma$ is the surface tension of the working fluid $(\mathrm{N} / \mathrm{m})$

- $\rho$ is the density of the working fluid $\left(\mathrm{kg} / \mathrm{m}^{3}\right)$

- $g$ is the gravitational acceleration $\left(\mathrm{m} / \mathrm{s}^{2}\right)$
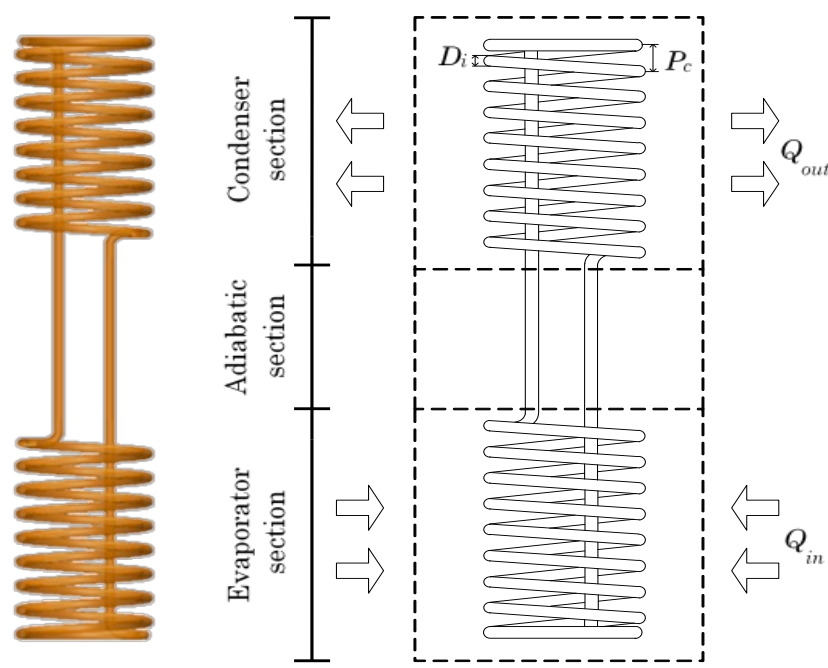

Fig. 2 The HOHP set up
If $D_{i} \leq D_{\max }$, surface tension forces dominate and stable liquid plugs are formed. However, if $D_{i}>D_{\max }$, the surface tension is reduced and the working fluid will stratify by gravity and oscillations will cease.

The structure of the HOHP was designed from a tube bent into coil shapes at the evaporator and the condenser sections of the copper tubes. The HOHP consisted of an evaporator section, an adiabatic section, and a condenser section. The physical parameters of the HOHP variables are defined as follows: inner diameter of loop heat pipe $\left(D_{i}\right)$, and coil pitch $\left(P_{c}\right)$ as shown in Fig. 2.

In order to thoroughly study the effects of all parameters on the heat flux to formulate a correlation to predict the heat transfer characteristics of the HOHP. The controlled and variable parameters are shown in Table 1.

Table 1

Controlled and variable parameters

\begin{tabular}{l}
\hline The controlled parameters \\
\hline - Inclination angle $(a)=90^{\circ}$ (the horizontal) \\
- Temperature of condenser section $\left(T_{c}\right)=25^{\circ} \mathrm{C}$ \\
- Adiabatic section length $\left(L_{a}\right)=100 \mathrm{~mm}$ \\
- Air velocity $(v)=1 \mathrm{~m} / \mathrm{s}$ \\
\hline The variable parameters \\
\hline - Temperature of evaporator section $\left(T_{e}\right)=60,70$, and $80^{\circ} \mathrm{C}$ \\
- Working fluid $=$ Water, Ethanol, and $\mathrm{R} 134 \mathrm{a}$ \\
- Filling ratio $=30 \%, 50 \%$, and $80 \%$ (by total internal \\
volume) \\
- Inner diameter $\left(D_{i}\right)=2.03,3.5$, and $4.5 \mathrm{~mm}$ \\
- lengths are equal $\left(L_{e}\right)=1500,2000$, and $2500 \mathrm{~mm}$ \\
\hline
\end{tabular}

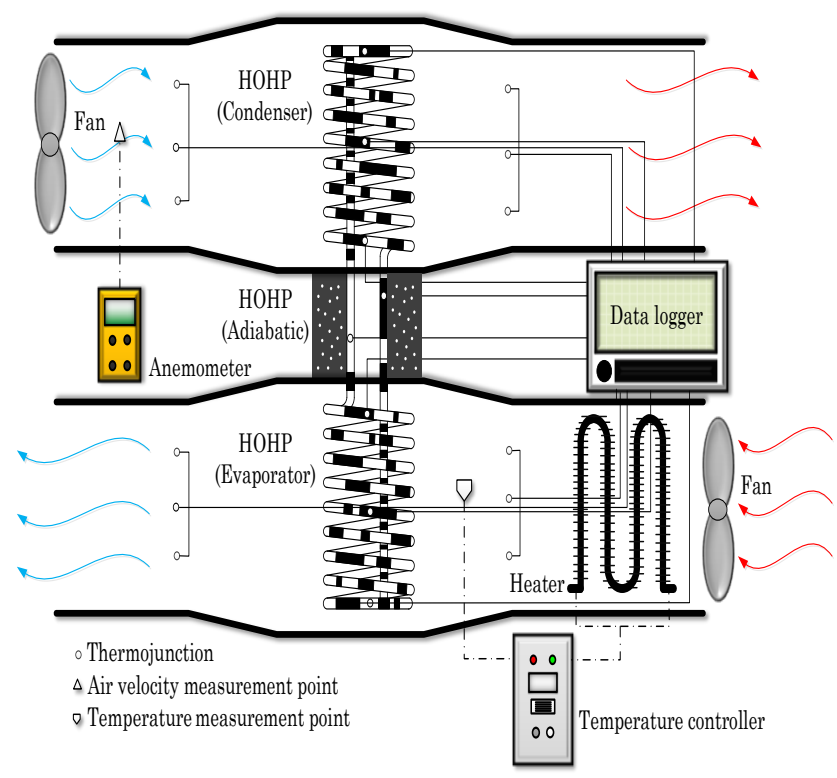

Fig. 3 Schematic diagram of experimental apparatus 
Citation: Donmuang, A. and Chompookham, T. (2021) Correlation for Predicting Heat Transfer Characteristics of a Helical Oscillating Heat Pipe (HOHP) at Normal Operating Conditions. Int. Journal of Renewable Energy Development, 10(2), 171-182; doi: 10.14710/ijred.2021.33671

$\mathrm{P}$ a g e | 174

\subsection{Heat transfer experimental apparatus}

The experiments were performed in an open-circuit airflow wind tunnel system operated in suction mode. Along its path of flow, air from the laboratory space passed through the test section, the air velocity through the tunnel was regulated by a blower from which it was discharged. The schematic diagram of experimental apparatus of the wind tunnel with the arrangement of tested HOHP is shown in Fig. 3.

After obtaining the schematic diagram of experimental apparatus, a test rig was created as shown in Fig. 4 and the HOHP was set up according to the parameters used in the experiment. As for the test, hot air from the heater was drawn into the evaporator section. Evaporator temperature $\left(T_{e}\right)$ was controlled by a temperature control unit and varied at 60,70 , and $80^{\circ} \mathrm{C}$. Air flowed from the fan through the air velocity meter into the condenser section. When the test system reached equilibrium, the temperature was measured at 15 different parts using the k-type thermocouple with $\pm 1.5^{\circ} \mathrm{C}$ deviation. The temperatures were recorded with Data logger (Yokogawa DX200) with $\pm 1^{\circ} \mathrm{C}$ deviation. The air velocity meter used was Testo model 445 with $\pm 0.05 \%$ deviation. Temperature measurement points consisted of hot air at evaporator section, adiabatic section, temperature control unit, environment temperature, inlet air to condenser section, and outlet air from condenser section. The inlet and outlet air temperatures at the condenser section can be used to calculate heat-transfer rates.

\subsection{Data analysis}

The HOHP can be used to determine the heat transfer rate in the condenser section by measuring the inlet and outlet air temperatures in the condenser section and can be calculated using the calorimetric method, as the following Eq. (2) (Thongdaeng et al. 2014).

$Q=\dot{m} C_{p}\left(T_{\text {out }}-T_{\text {in }}\right)$

where:

- $Q$ is the heat transfer rate (W)

- $\dot{m}$ is the mass flow rate of the air $(\mathrm{kg} / \mathrm{s})$

- $C_{p}$ is the specific heat of the air $\left(\mathrm{J} / \mathrm{kg} .{ }^{\circ} \mathrm{C}\right)$

- $T_{\text {out }}$ is the outlet air temperature of condenser section $\left({ }^{\circ} \mathrm{C}\right)$

- $\quad T_{\text {in }}$ is the inlet air temperature of condenser section $\left({ }^{\circ} \mathrm{C}\right)$

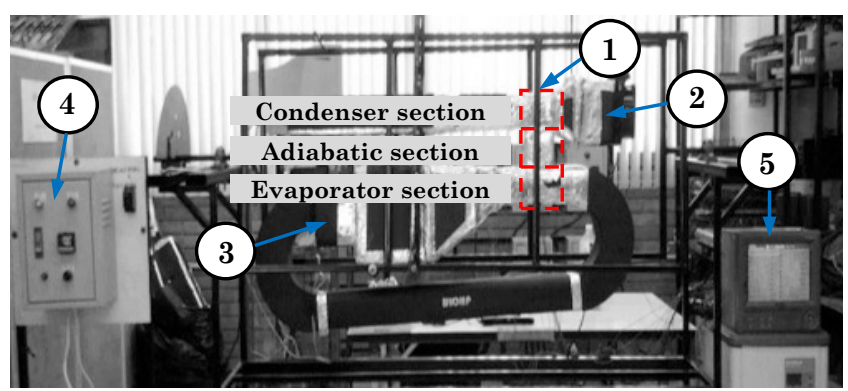

Fig. 4 The test rig; (1)- HOHP, (2-3)- fan, (4)-Temperature controller, and (5)- Data logger
The heat flux was calculated using the Eq. (3), (Bhuwakietkumjohn and Rittidech 2010).

$q=\frac{Q}{A_{c}}=\frac{Q}{\Pi D_{o} L_{c}}$

where:

- $q$ is the heat flux $\left(\mathrm{W} / \mathrm{m}^{2}\right)$

- $Q$ is the heat transfer rate (W)

- $D_{o}$ is the outside diameter of the tube (m)

- $A_{c}$ is the total outside area of the tube $\left(\mathrm{m}^{2}\right)$

- $L_{c}$ is the condenser section length (m)

The mass flow rate of the air can be determined using equation (4).

$\dot{m}=\rho v A$

where:

- $\rho$ is the air density $\left(\mathrm{kg} / \mathrm{m}^{3}\right)$

- $v$ is the air velocity $(\mathrm{m} / \mathrm{s})$

- $\mathrm{A}$ is the cross-section area of air flow $\left(\mathrm{m}^{2}\right)$

In the correlation to predict heat transfer characteristics of the HOHP a dimensionless Kutateladze number $(\mathrm{Ku})$ is applied to analyze a correlation from the dimensionless parameters group (Rittidech et al. 2003). The dimensionless parameters of interest, which may have an effect on the heat flux of a HOHP are $\rho_{v} / \rho_{l}, B o, N u, W e$, $J a, P r, F r, C o, G a, B i$, Wo, and $O h$. Thus, the thermal performance of the HOHP is expressed as the Eq (5-6).

$$
\begin{gathered}
q=f\left(\rho_{v} / \rho_{l}, \mathrm{Bo}, \mathrm{Nu}, \mathrm{We}, \mathrm{Ja}, \operatorname{Pr},\right. \\
F r, \mathrm{Co}, \mathrm{Ga}, \mathrm{Bi}, \mathrm{Wo}, \mathrm{Oh})
\end{gathered}
$$

where:

- $\quad \rho_{v}$ is the working fluid density of vapor $\left(\mathrm{kg} / \mathrm{m}^{3}\right)$

- $\quad \rho_{l}$ is the working fluid density of liquid $\left(\mathrm{kg} / \mathrm{m}^{3}\right)$

- $\quad$ Bo is the Bond number (-)

- $\quad N u$ is the Nusselt number (-)

- We is the Weber number (-)

- $\quad J a$ is the Jacob number (-)

- $\quad \operatorname{Pr}$ is the Prandtl number (-)

- $\quad F r$ is the Froude number (-)

- $\quad C o$ is the Condensation number (-)

- $G a$ is the Galileo number (-)

- $\quad B i$ is the Biot number (-)

- Wo is the Wo number (-)

- $\quad$ Oh is the Ohnesorge number (-)

$q=K u \times\left[\rho_{v} h_{f g}\left(\frac{\rho_{l}-\rho_{v}}{\rho_{v}^{2}}\right)\right]^{1 / 4}$

where:

- $h_{f g}$ is the latent heat of vaporization $(\mathrm{kJ} / \mathrm{kg})$

- $\quad K u$ is the kutateladze number (-) 
Table 2

The uncertainty analysis result

\begin{tabular}{|c|c|c|c|c|}
\hline Quantity source of uncertainty & $\begin{array}{l}\text { Thermocouple type } \mathrm{K} \\
{\left[{ }^{\circ} \mathrm{C}\right]}\end{array}$ & $\begin{array}{l}\text { Data logger } \\
{\left[{ }^{\circ} \mathrm{C}\right]}\end{array}$ & $\begin{array}{l}\text { Uncertainty of mean } \\
\text { reading }\left[{ }^{\circ} \mathrm{C}\right]\end{array}$ & $\begin{array}{l}\text { Air flow meter } \\
{[\mathrm{m} / \mathrm{s}]}\end{array}$ \\
\hline Uncertainty type & Type B & Type B & Type A & Type B \\
\hline Value of quantity & $-270-1,372$ & $-200-1,100$ & - & $0.4-60$ \\
\hline Confidence Level (\%) & 95 & 95 & 95 & 95 \\
\hline Converge Factor $(k)$ & 2 & 2 & 2 & 2 \\
\hline Standard Uncertainty $\left(u_{i}\right)$ & 0.5773 & 0.578 & 0.2775 & 0.1155 \\
\hline Sensitivity Coefficient $\left(c_{i}\right)$ & 1 & 1 & 1 & 1 \\
\hline Uncertainty Component $\left(u_{i} c_{i}\right)$ & 0.5773 & 0.578 & 0.245 & 0.1155 \\
\hline Combined Uncertainty $\left(u_{c}\right)$ & 0.6978 & 0.698 & 0.69784 & - \\
\hline Expanded uncertainty $(U)$ & 1.3956 & 1.395 & 1.3956 & - \\
\hline
\end{tabular}

\subsection{Uncertainty analysis}

Calculating standard uncertainty for a type-A evaluation. When a set of several repeated readings were taken (for a Type-A estimate of uncertainty), (Arithmetic mean), $S D$ (Standard deviation), can be calculated by the Eq. (7-9) (Pipatpaiboon et al. 2012).

$$
\begin{aligned}
& \bar{x}=\frac{x_{1}+x_{2}+\ldots .+x_{n}}{n_{s}} \\
& S D=\frac{\sqrt{\left(x_{1}-\bar{x}\right)^{2}+\left(x_{2}-\bar{x}\right)^{2}+\ldots .+\left(x_{n}-\bar{x}\right)^{2}}}{n_{s}-1} \\
& u_{i, \text { typeA }}=\frac{S D}{\sqrt{n_{s}}}
\end{aligned}
$$

where $n_{s}$ is the number of measurements in the setup. Calculating standard uncertainty for a type-B evaluation. Using the following Eq. (10).

$$
u_{i, t y p e B}=\frac{a}{\sqrt{3}}
$$

where $a$ is the semi range (or half-width) between upper and lower limit. Combined standard uncertainty calculated by Type-A and Type-B evaluations can be combined as shown by $u_{c}$ Eq. (11).

$$
u_{c}=\sqrt{\left(u_{i, t y p e A}\right)^{2}+\left(u_{i, t y p e B}\right)^{2}+\ldots .+e t c .}
$$

A particular value of coverage factor gives a particular confidence level for the expanded uncertainty. Most commonly, overall uncertainty using the coverage factor $k$ $=2$ to give a level of confidence of approximately $95 \%$. $(k=$ 2 is correct if the combined standard uncertainty is normally distributed). Some other coverage factors (for a normal distribution) are:

$k=1$ for a confidence level of approximately $68 \%$

$k=2.5$ for a confidence level of $99 \%$ $k=3$ for a confidence level of $99.7 \%$

The uncertainty analysis result for this study is shown in Table 2.

\section{Results and Discussion}

The results of the study of the effects of inner diameter, section length, pitch coil, filling ratio, working fluid and the correlation equation from the dimensionless parameters on the heat transfer characteristics of the HOHP were considered in this research. The experimental results can be presented as follows.

\subsection{Effect of geometrical size}

The geometrical size of a HOHP consisting of the inner diameter, pitch coil and section length were considered in this research. It can be divided into three categories as follows.

\subsubsection{Effect of inner diameter of HOHP}

In this experiment, the inner diameters used were 2.03, 3.5 , and $4.5 \mathrm{~mm}$. It was assumed that the maximum inner diameter of the capillary tube in which the vapor and liquid slug alternately formed depended on the properties of the working fluid as shown by Eq. (1). The experimental results clearly present the effect of inner diameter on heat flux as shown in Fig. 5. In the figure, a relationship of the inner diameter with the heat flux of the HOHP with R134a as working fluid, evaporator length of $2500 \mathrm{~mm}$ and $80 \%$ by filling ratio of working fluid using various temperatures in evaporator section operating at vertical position can be observed. It can be seen that as the inner diameter increased, but the heat flux decreased and the maximum flux was obtained at inner diameter of $2.03 \mathrm{~mm}$. The heat flux values were 2694,2280 , and $1867 \mathrm{~W} / \mathrm{m}^{2}$ for temperature of evaporator section of 80,70 , and $60^{\circ} \mathrm{C}$, respectively. It was thought that the vapor slug filled the cross-section area within the tube with the working fluid, whereas their operation is based on the principle of oscillation for the working fluid and a phase change phenomenon in the capillary tube. It can be concluded that the smaller the inner diameter the higher the heat flux. 


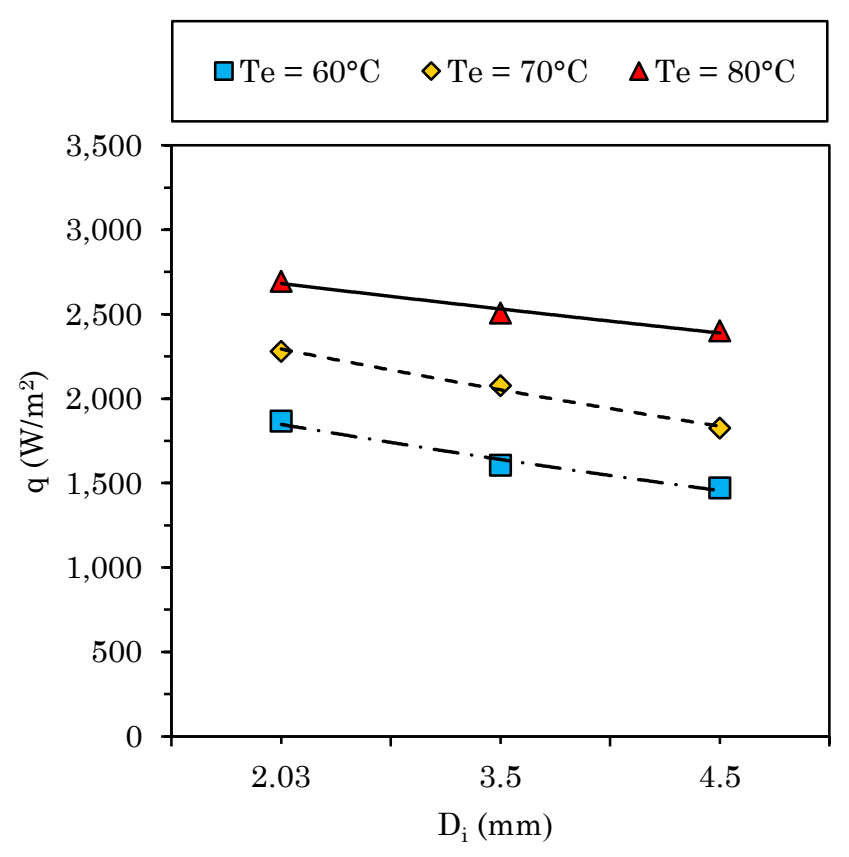

Fig. 5 Relationship between heat flux of HOHP and inner diameter

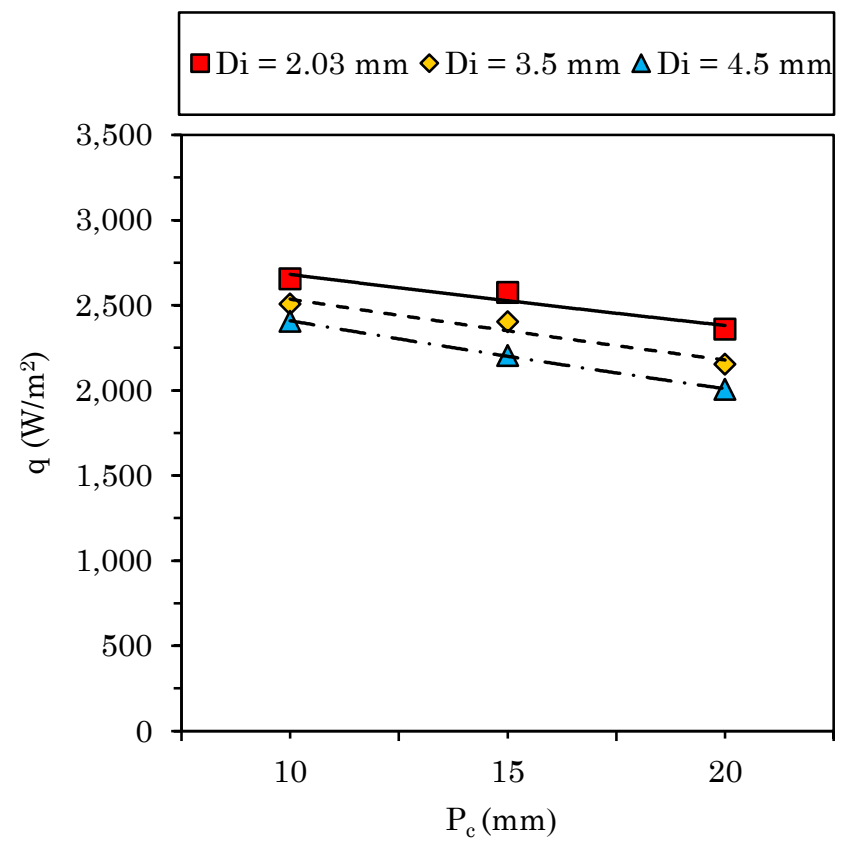

Fig. 6 Relationship between heat flux of HOHP and pitch coil

\subsubsection{Effect of pitch coil of HOHP}

Fig. 6 shows the relationship between the pitch coil and the heat flux of HOHP operating at vertical position with pitch coil of 10,15 , and $20 \mathrm{~mm}$, R134a as working fluid, $80 \%$ of filling ratio, evaporator length of $2500 \mathrm{~mm}$ and temperature of evaporator section of $80^{\circ} \mathrm{C}$. The inner diameters using various because it is the temperature of evaporator that gives the maximum heat transfer rate in this research. It was observed that the heat flux at each inner diameter decreased as the pitch coil increased. The maximum heat flux was obtained at the pitch coil of 10 $\mathrm{mm}$. The heat flux values were 2694,2508 , and $2406 \mathrm{~W} / \mathrm{m}^{2}$ for inner diameter of $2.03,3.5$, and $4.5 \mathrm{~mm}$, respectively. This is because, when the pitch increased it was difficult for the slug flow blocks to transport down the slope of the tube due to the higher driving force needed to overcome the force of gravity and to push the slug flow up to the evaporator section for heat transfer. This directly affected the value of the results as well.

\subsubsection{Effect of condenser and evaporator section lengths of $\mathrm{HOHP}$}

In this experiment, the evaporator and condenser were of equal lengths. As a result, the heat flux at the evaporator and condenser of the HOHP were also equal. The effect of section length on the heat flux is shown in Fig. 7. In the figure, the relationship of the section lengths with the heat flux of the HOHP with R134a as working fluid and 80\% filling ratio, using various inner diameters at vertical position can be observed. It can be seen that as the evaporator length increased, the heat flux increased in all the working fluids. The maximum heat flux was obtained at the section length of $2500 \mathrm{~mm}$. The heat flux values were 2694,2407 , and $2267 \mathrm{~W} / \mathrm{m}^{2}$ for inner diameter of $2.03,3.5$, and $4.5 \mathrm{~mm}$, respectively. As the condenser and evaporator length increases, the heat flux increases with all interner diameters. From a previous research (Katpradit et al. 2005), an explanation was found that when the section length increased the slug flow that had formed inside the tube would be longer (liquid at the vapor-liquid interface evaporated rapidly) and the vapor bubbles did not easily move to the condenser section. In addition, the liquid inside the vapor bubbles quickly evaporated into the condenser section and held the liquid that returned from the condenser back in the evaporator. For this reason, the amount of liquid in the evaporator section was insufficient and a dry-out occurred. Therefore, to solve this problem, the evaporator and condensation sections were bent into helical shapes.

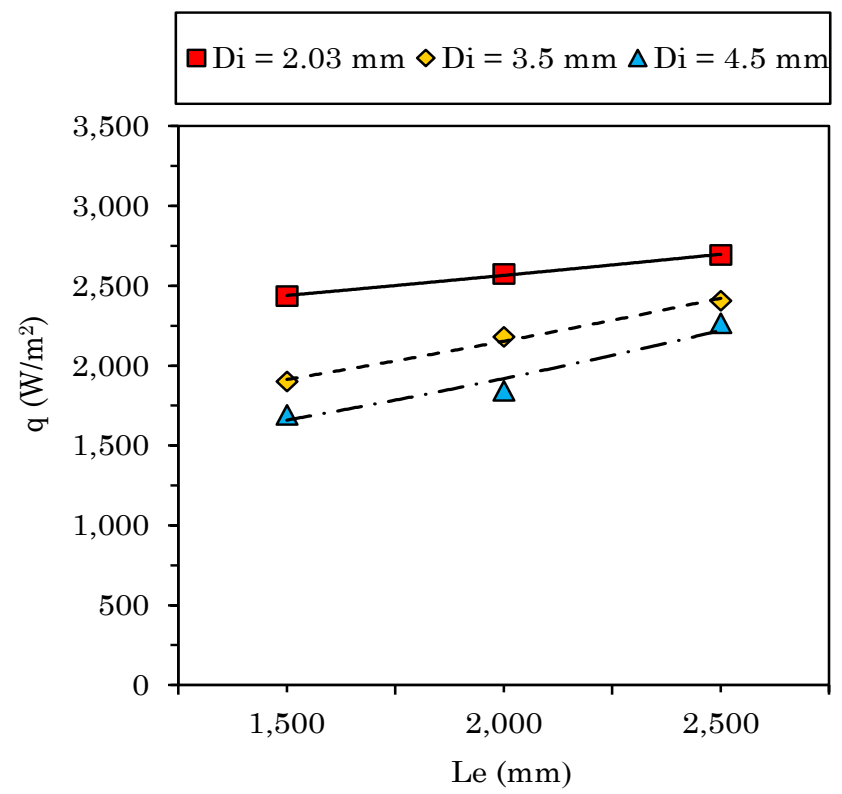

Fig. 7 Relationship between heat flux of HOHP and evaporator length 


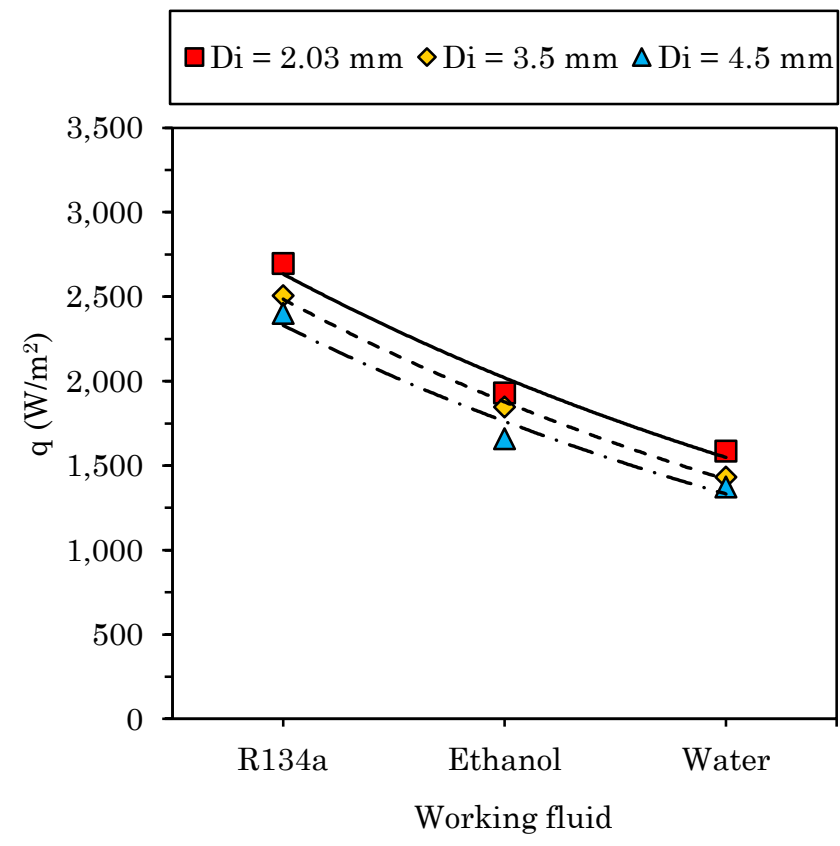

Fig. 8 Relationship between heat flux of a HOHP and working fluids

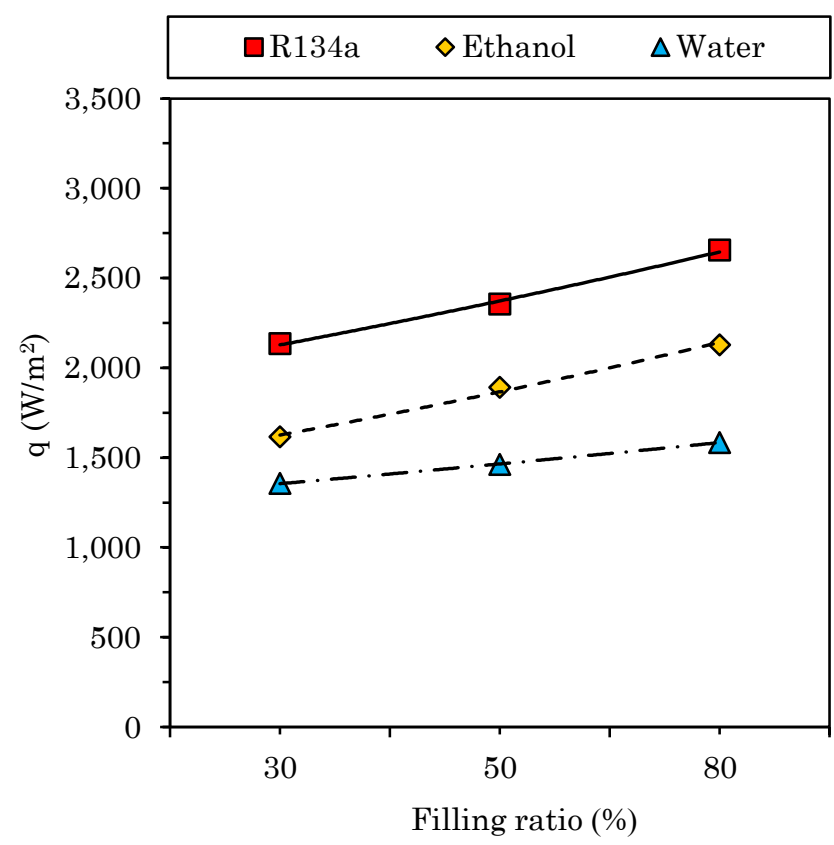

Fig. 9 Relationship between heat flux of a HOHP and filling ratios

\subsection{Effect of working fluid}

Three types of working fluids used were R134a, ethanol, and water. Their thermodynamic properties are different such that specific heat should produce different effects on the rate of heat transfer of a HOHP. The specific heat of water, ethanol, and R134a is in descending order and cover on applications. It was found from the experimental data that good trends of relationship could be obtained. Fig. 8 presents the effect of working fluid on heat flux of the HOHP. This figure shows the relationship between the working fluid and the heat flux of the HOHP with an inner diameter of $2.03 \mathrm{~mm}$, an evaporator length of $2500 \mathrm{~mm}$, a temperature of evaporator of $80^{\circ} \mathrm{C}$ and in a vertical position. It was observed that the heat flux increased as the specific heat of working fluid decreased. For the different amounts of inner diameter, the maximum heat flux was obtained at the specific heat of $2.07 \mathrm{~kJ} / \mathrm{kg} . \mathrm{K}$ (R134a). Those values were 2694, 2505, and $2401 \mathrm{~W} / \mathrm{m}^{2}$ for inner diameter of $2.03,3.5$, and $4.5 \mathrm{~mm}$, respectively. This is because, as the specific heat decreases the pressure at the evaporator section becomes low. Because of this, the liquid phase of the working fluid changes rapidly into the vapor phases. Thus, the working fluid can affect the heat transfer and the heat flux also. Where the results were consistent with the results of the numerical model of the HOHP obtained by (Siriwan et al. 2017) at filling ratio of $80 \%$ by total volume. When replacing the working fluid, ethanol is used instead of water which increases the heat transfer rate.

\subsection{Effect of filling ratio}

In this experiment, the filling ratios used were 30,50 , and $80 \%$ by total volume. The experimental results that present the effect of the filling ratio on the heat flux are in Fig. 9. In the figure a relationship of the filling ratio with the heat flux of the HOHP with inner diameter of $2.03 \mathrm{~mm}$, an evaporator length of $2500 \mathrm{~mm}$, pitch coil of $10 \mathrm{~mm}$ and $80 \%$ filling ratio using various working fluids operating at vertical position can be observed. The maximum heat flux of all the filling ratio was obtained at the maximum filling ratio of $80 \%$ by total volume. Those values were 2694 , 2130 , and $1585 \mathrm{~W} / \mathrm{m}^{2}$ for working fluids of R134a, ethanol, and water, respectively. This is because, the quantity of space in the tube and the working fluid were equal so it was suitable for the boiling of the working fluid and the bubbles could flow easily resulting in the best heat transfer rate, followed by the filling ratio of working fluid of $80 \%$ by total volume. The volume of working fluid inside the tube caused a lot of vapor bubble causing the heat flux value to be higher than the filling rate of $30 \%$ and $50 \%$ by total volume. Therefore, the filling ratio of working fluid at $80 \%$ by total volume using R134a as working fluid gave the maximum heat flux.

\subsection{Effect of dimensionless parameters}

The correlation of dimensionless parameters can be evaluated from the discussion of the effect of the important dimensionless parameters. It was found that the experimental results of the HOHP at normal operating conditions in vertical position consisted of a group of the dimensionless parameters were Bond number, $B o$, Nusselt number, $N u$, Weber number, We, Wo number, Wo, Prandtl number, $P r$, Galileo number, $G a$, Condensation number, Co, Jacob number, Ja, Froude number, Fr, Ohnesorge number, $O h$, Biot number, $B i$, ratio of vapor density to liquid density, $\rho_{v} / \rho_{l}$. Bo is the ratio of buoyancy force per surface tension force. The $B o$ values can be used to explain boiling phenomena inside the evaporator section and represent the state of vapor bubbles that occur in nucleate boiling. When the evaporator receives heat, the surface tension of the working fluid inside is reduced causing the buoyancy force to dominate the surface tension. 
Citation: Donmuang, A. and Chompookham, T. (2021) Correlation for Predicting Heat Transfer Characteristics of a Helical Oscillating Heat Pipe (HOHP) at Normal Operating Conditions. Int. Journal of Renewable Energy Development, 10(2), 171-182; doi: 10.14710/ijred.2021.33671

P a g e | 178

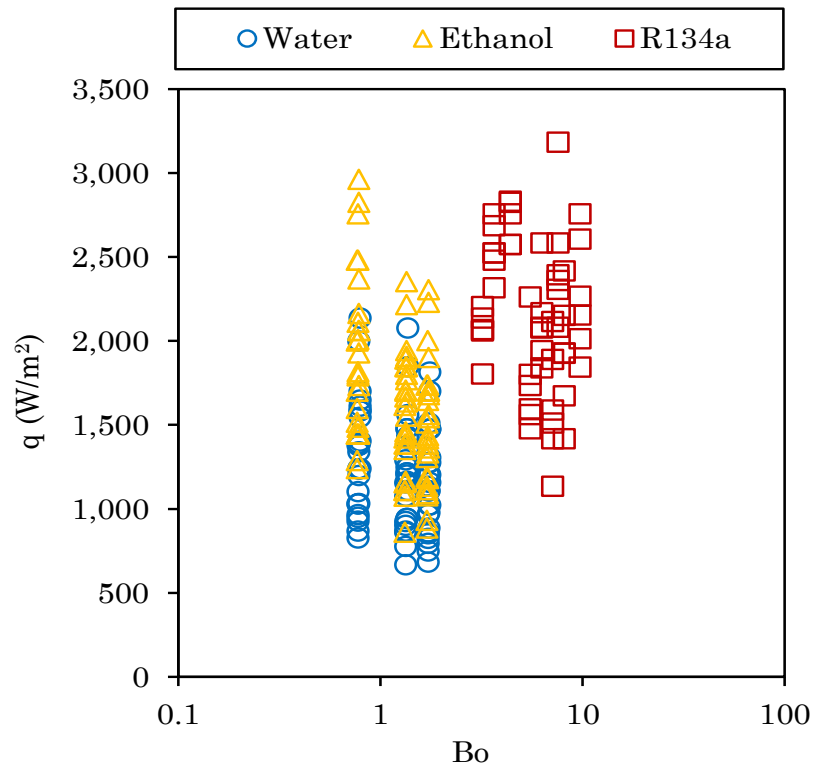

(a)

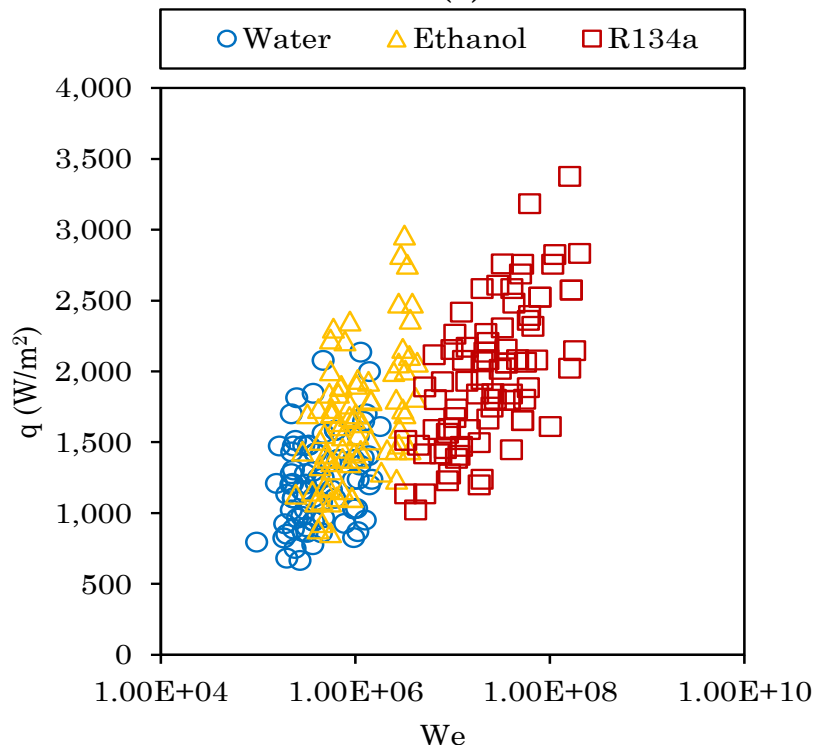

(c)

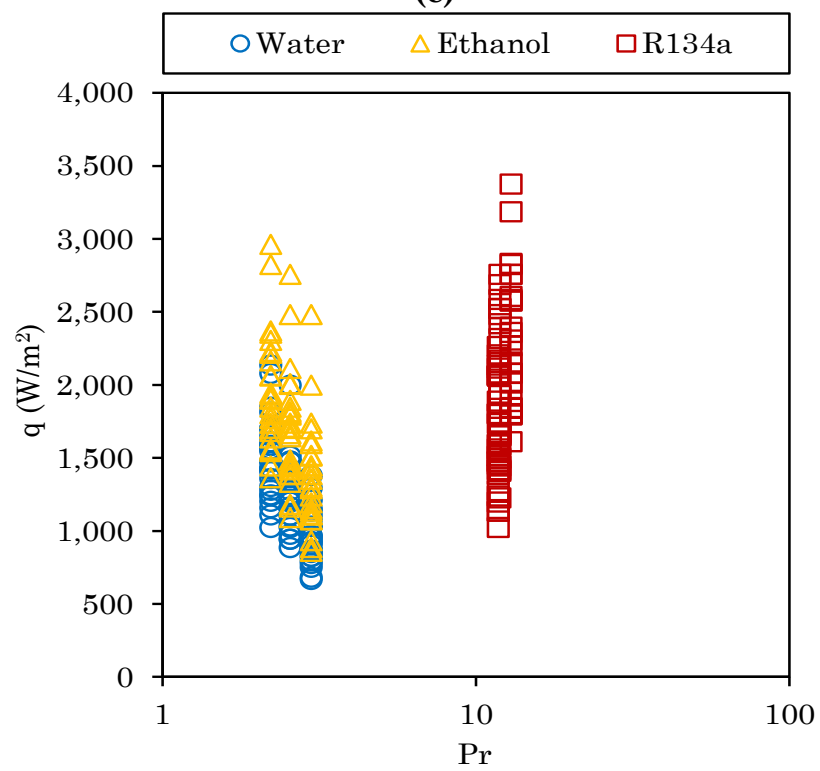

(e)

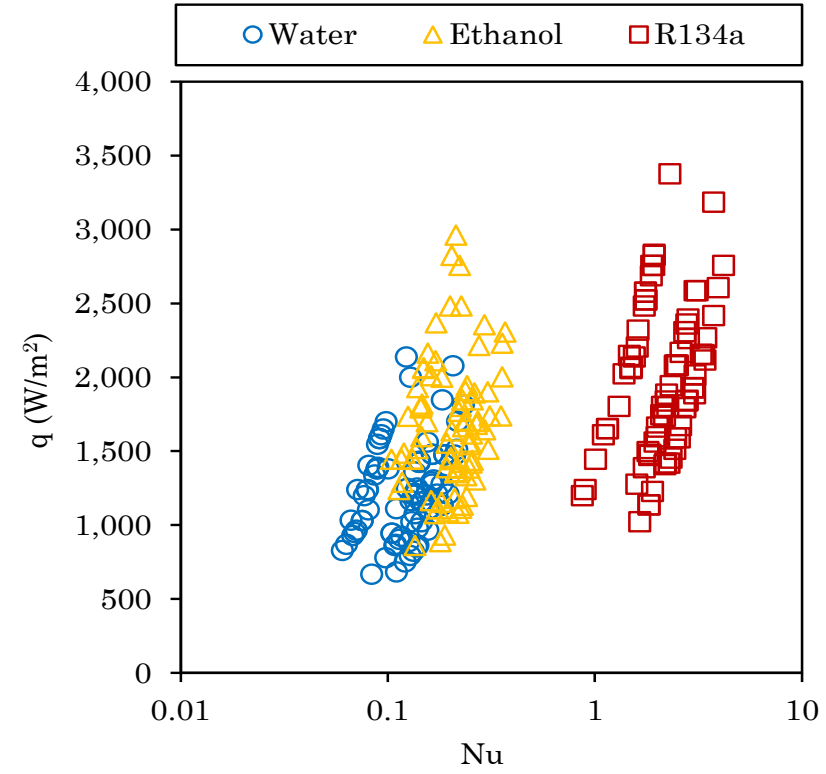

(b)

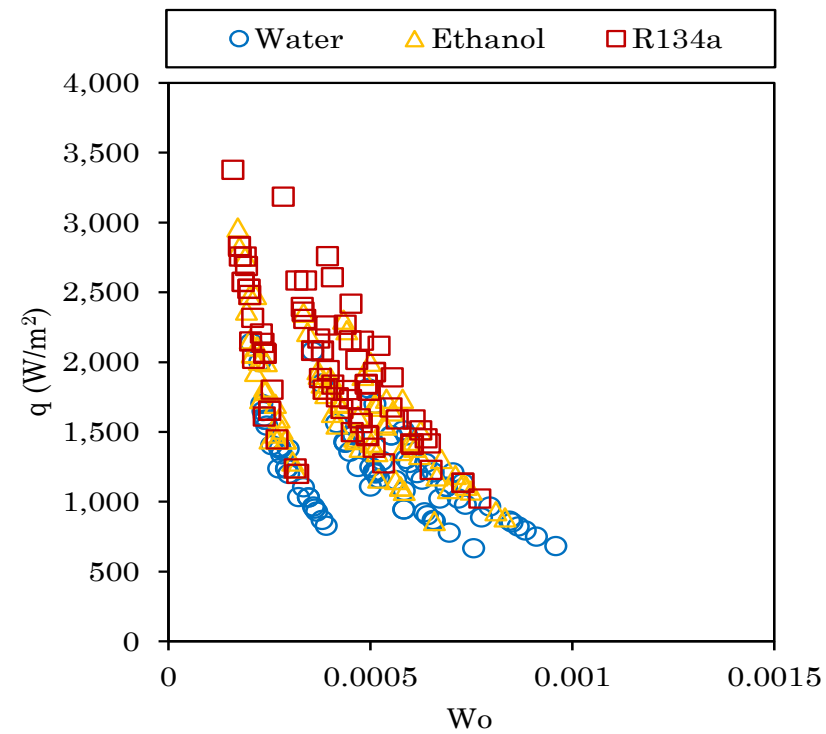

(d)

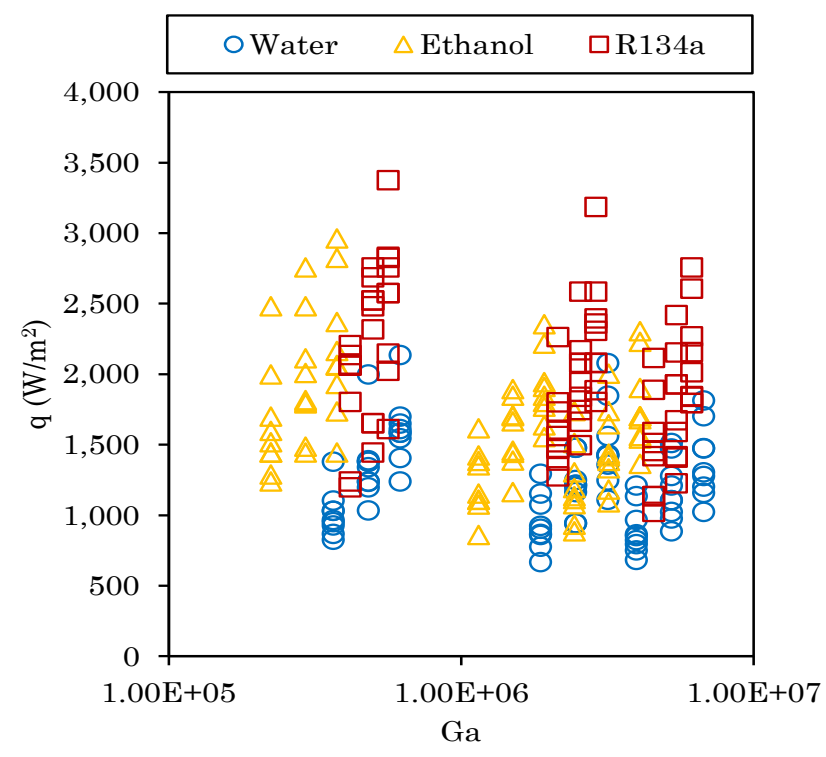

(f) 


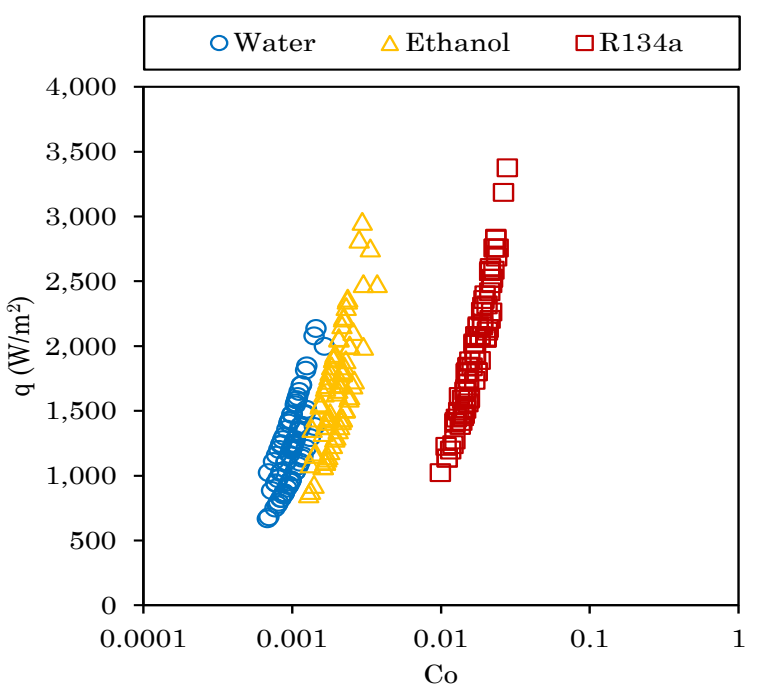

(g)

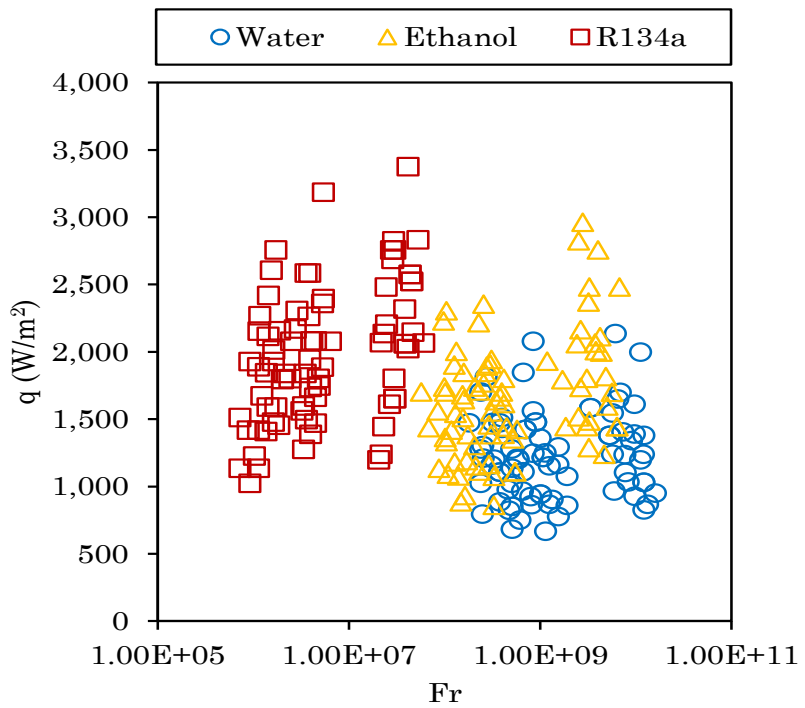

(i)

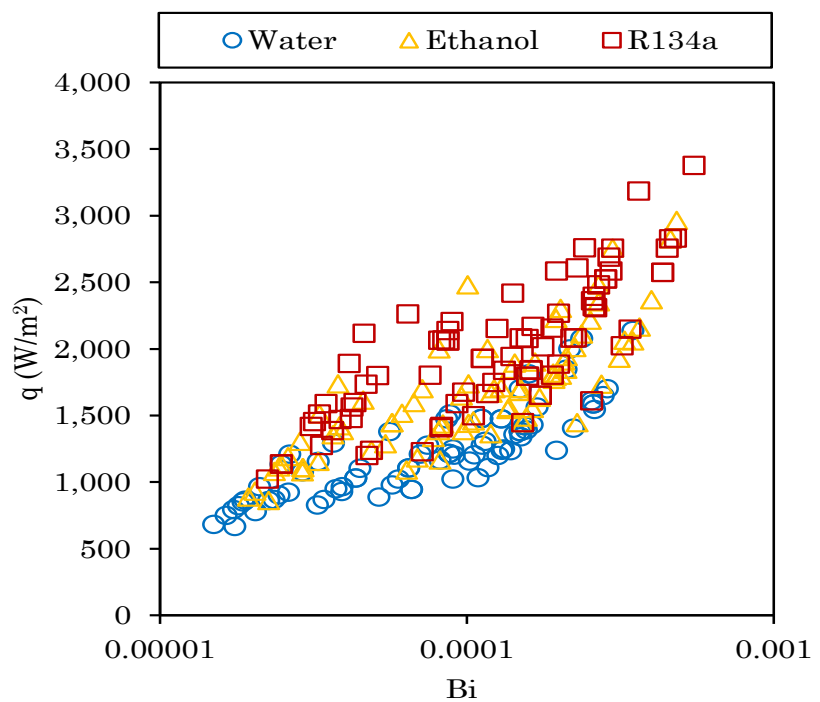

(k)

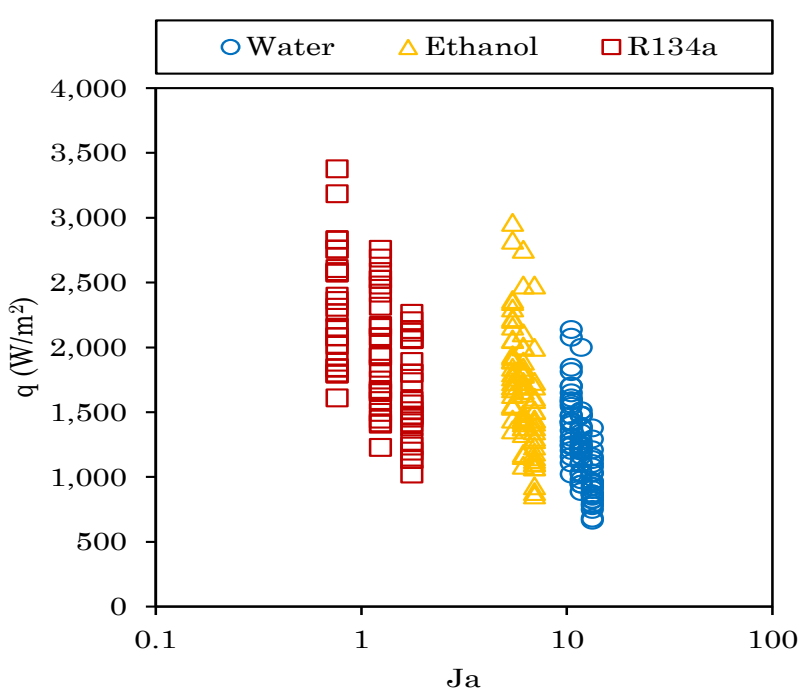

(h)

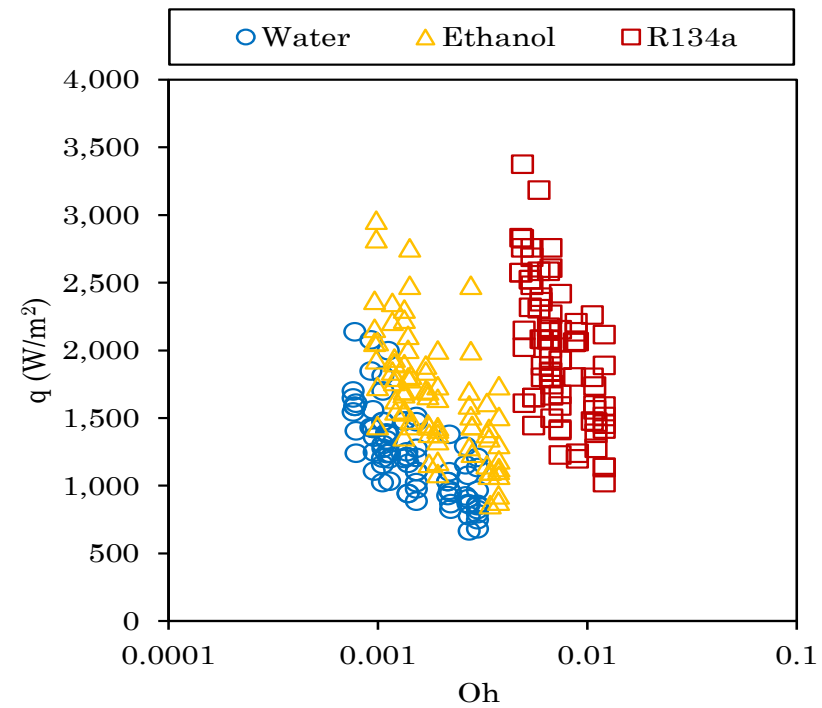

(j)

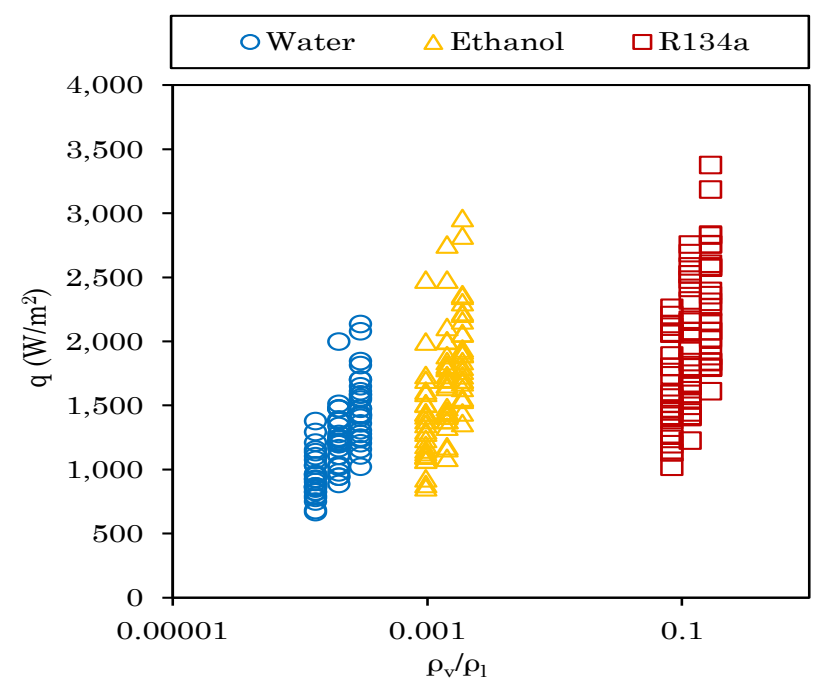

(1)

Fig. 10 Relationship between heat flux of a HOHP and dimensionless parameters: (a) Bond number (Bo); (b) Nusselt number (Nu); (c) Weber number (We); (d) Wo number (Wo); (e) Prandtl number (Pr); (f) Galileo number (Ga); (g) Condensation number (Co); (h) Jacob number (Ja); (i) Froude number (Fr); (j) Ohnesorge number (Oh); (k) Biot number (Bi); (l) $\rho_{v} / \rho$ 


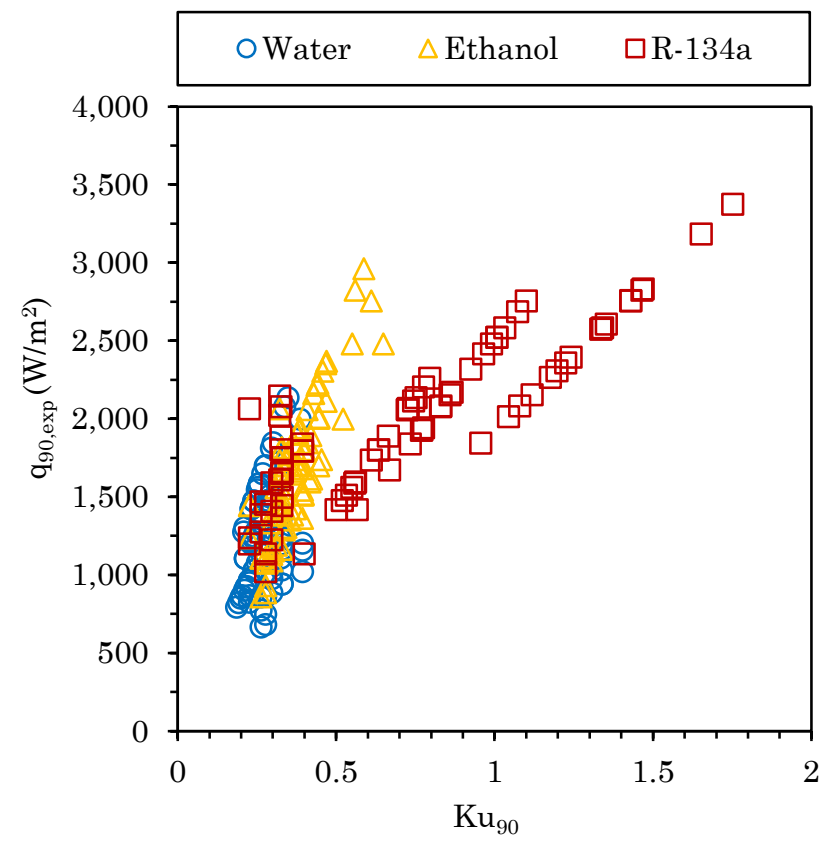

Fig. 11 Relationship between heat flux of a HOHP and $K u$

If the Bo value is high, the working fluid boils vigorously (Parametthanuwat et al. 2010). The Bo value of the HOHP depends on density and type of working fluid of the HOHP. It was found that the relationship between the $B o$ and heat flux of the HOHP was that when the type of working fluid were changed to water, ethanol and R134a, the heat flux increased, respectively, as shown in Fig. 10(a). $N u$ is the ratio of convection heat transfer to fluid conduction heat transfer under the boundary. The $N u$ is the conductive component measured under the same conditions as the heat convection but with a (hypothetically) stagnant (or motionless) fluid, as shown in Fig. 10(b). We is the inertia to surface tension forces (Bergman et al. 2011). It represents the counter-current interactions between free surface of liquid film and vapor flows inside the HOHP. The $W e$ is an important dimensionless parameters in a two-phase flow which occur in both the evaporator and condenser sections of HOHP, as shown in Fig. 10(c). Wo is the ratio of the dimension of the diameter per the pulsatile frequency. $W o$ is a dimensionless expression of the pulsatile flow frequency in relation to viscous effects, as shown in Fig. 10(d). Pr is the ratio of momentum diffusivity per thermal diffusivity of liquid. $\operatorname{Pr}$ represents convection heat-transfer in a tube. It may occur when the vapor bubble moves from the evaporator section to the condenser section. If the value of $\mathrm{Pr}$ is very low, the heat-transfer of the vapor bubbles will be much higher than its momentum transfer because the vapor bubbles will be able to transfer the thermal energy to condenser section efficiently, as shown in Fig. 10(e). Ga is the ratio of forces present in the flow of viscous fluids, as shown in Fig. 10(f). Co is the ratio of liquid density and hence gravitational component and homogeneous theory for the momentum component (heat flux divided by the product of mass flux and latent heat of vaporization), as shown in Fig. $10(\mathrm{~g}) . J a$ is the ratio of latent heat to sensible heat of the working fluid, as shown in Fig. 10(h). $\mathrm{Fr}$ is the ratio of dynamic viscosity to weight, as shown in Fig. 10(i). Oh is the ratio of viscous force to the square root of the product of inertial and surface forces, as shown in Fig. 10(j). Bi is the ratio of the internal thermal resistance of a solid to the boundary layer thermal resistance, as shown in Fig. $10(\mathrm{k}) . \rho_{v} / \rho_{l}$ is the ratio of vapor density to liquid density of the working fluid, as shown in Fig. 10(l).

$K u$ is the ratio of HOHP output heat flux per critical heat flux of a working fluid and it represents the pool boiling phenomenon of the working fluid in the evaporator section. Fig. 11 shows the relationship between $K u$ values and heat flux from the experiment. It can be seen that the relationship between the $K u$ values and the heat flux of the entire working fluid were similar. Firstly, they were linear. Secondly, when the value of $K u$ increased heat flux increased as well. Thus, the dimensionless parameters can be used to formulate a correlation to predict the heat flux of a HOHP at normal operating conditions in vertical position.

\subsection{Correlation equations}

It was found from the experimental results of the effect of dimensionless parameters on heat transfer characteristics of the HOHP thus, $\rho_{v} / \rho_{l}, \mathrm{Bo}, \mathrm{Nu}, \mathrm{We}, \mathrm{Ja}, \mathrm{Pr}, \mathrm{Fr}, \mathrm{Co}, \mathrm{Ga}$, $B i, W o, O h$, and $K u$ values can be used to formulate a correlation to predict heat-transfer rates of the HOHP. The correlation of dimensionless parameters, as shown in Fig. 12.

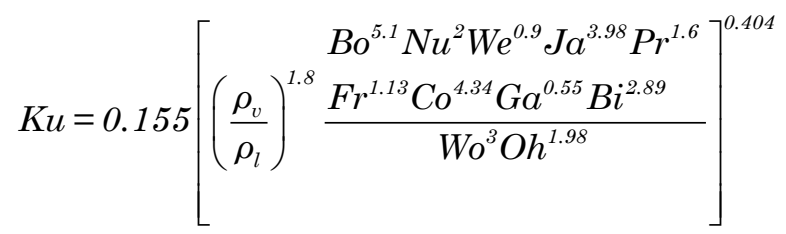

The coefficient of determination $\left(\mathrm{R}^{2}\right)$ of this equation was 0.89. Fig. 13 shows a comparison between heat flux from the experiment and heat flux from the prediction using Eq. (12).

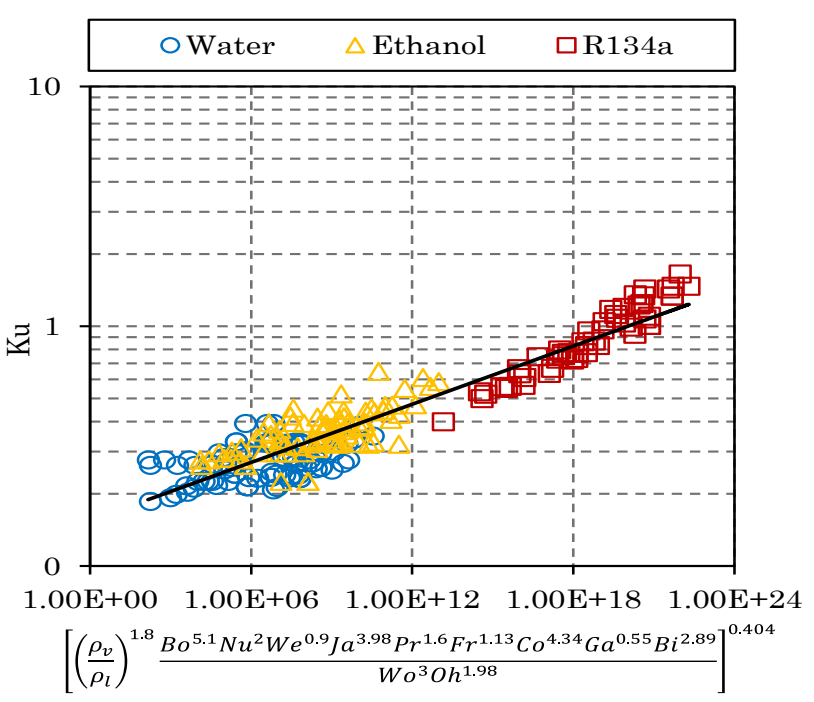

Fig. 12 Solid line represents the correlation: Eq. (10) 


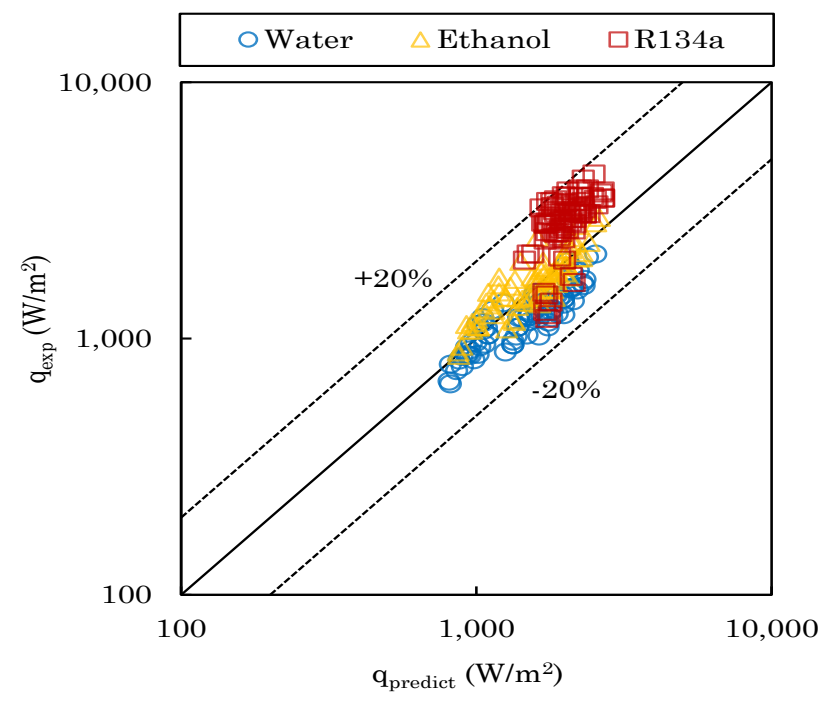

Fig. 13 Comparison of heat flux of a HOHP in experimental and prediction

\section{Conclusion}

In this paper, the experiments were implemented to study the heat transfer characteristics of a HOHP at a vertical position. The effects of various parameters were applied on the heat flux of the HOHP. The results showed that the heat flux of HOHP was basically changed with the working fluid, while the heat flux of HOHP decreases with an increase of an inner diameter and the pitch coil, but the heat flux of HOHP increases with the increase of the condenser/evaporator section length and the filling ratio. It can be concluded that of the maximum heat flux of the various parameters were as follows: the working fluid was $\mathrm{R} 134 \mathrm{a}$, the inner diameter was $2.03 \mathrm{~mm}$, the pitch coil was $10 \mathrm{~mm}$, the condenser/evaporator section length was 2500 $\mathrm{mm}$, and the filling ratio was $80 \%$ of the total internal volume. The dimensionless parameters were $\rho_{v} / \rho_{l}, B o$, $\mathrm{Nu}$, We, Ja, $\mathrm{Pr}, \mathrm{Fr}, \mathrm{Co}, \mathrm{Ga}, \mathrm{Bi}, \mathrm{Wo}, \mathrm{Oh}$, and $\mathrm{Ku}$ that affect heat flux of the HOHP were obtained. Afterward, a powerlaw correlation based on dimensionless groups was established to predict the input heat flux of the HOHP using available experimental data sets of the HOHP.

From this research, a correlation equation can be applied to design a helical oscillating heat pipe of heat exchanger for applications using air preheater to the waste heat recovery. The advantage of the HOHP is its convenient monitoring and maintenance. Because HOHPs are not connected, they damage one set at a time, causing the heat exchanger to work yet, but in lower performance. However, the HOHP limit of use will be subject to the conditions of this research, such as working fluid, inner diameter, pitch coil, evaporator temperature, evaporator and inclination angle. Currently, research on the heat exchanger uses the HOHP lacks the correlation equation used to design this type of heat exchanger for application. Therefore, this research will help to fill in this section.

\section{Acknowledgments}

This research was Conducted at the Heat Pipe and Thermal Tool Design Research Unit (HTDR), Faculty of Engineering, Mahasarakham University,
Mahasarakham, Thailand. The authors would like to express their appreciation to Rajamangala University of Technology Isan for providing financial support.

\section{References}

Adami, M. and Yimer, B. (1990) Development and evaluation of a planar heat pipe for cooling electronic systems. Chemical Engineering Communications, 90(1), 57-74.

Akachi, H., Polasek, F. and Stulc, P. (1996) Pulsating heat pipe. in Proc. of the $5^{\text {th }}$ International Heat Pipe Symposium, Australia, 208-217.

Aydin, D.Y., Gürü, M., Sözen, A. and Çiftçi, E. (2020) Thermal performance improvement of the heat pipe by employing dolomite/ethylene glycol nanofluid. Int. Journal of Renewable Energy Development, 9(1), 23-27.

Bergman, T.L., Lavine, S.A., Incropera, F.P. and Dewitt, D.P. (2011) Fundamentals of Heat and Mass Transfer, $7^{\text {th }}$ ed.; John Wiley \& Sons: United States of America.

Bhuwakietkumjohn, N. and Rittidech, S. (2010) Internal flow patterns on heat transfer characteristics of a closed-loop oscillating heat-pipe with check valves using ethanol and a silver nano-ethanol mixture. Experimental Thermal and Fluid Science, 34, 1000-1007.

Charoensawan, P. and Terdtoon, P. (2008) Thermal performance of horizontal closed-loop oscillating heat pipes. Applied Thermal Engineering, 28(5-6), 460-466.

Cheng, P. and Ma, H. (2011) A mathematical model of an oscillating heat pipe. Heat Transfer Engineering, 32(11), 1037-1046.

Donmuang, A., Chompookham, T. and Rittidech, S. (2014) Experimental study of heat transfer characteristics form vertical helical loop heat pipe. in the $10^{\text {th }}$ Mahasarakham University Research Conference, Thailand, 59.

Donmuang, A., Meena, P. and Rittidech, S. (2008) Closed-loop oscillating heat pipe with check valve (CLOHP/CV) heat exchanger for pre-heat glycerin oil in Chinese black syrup boiling process. in The $9^{\text {th }}$ International Heat Pipe Symposium, Bandar Sunway, Malaysia, 190-192.

Hassan, H. and Harmand, S. (2013) A Three-Dimensional Study of Electronic Component Cooling Using a Flat Heat Pipe. Heat Transfer Engineering, 34(7), 596-607.

Hoseinzadeh, S., Bahrami, A., Mirhosseini, S.M. and Sohani, A. (2020) A detailed experimental airfoil performance investigation using an equipped wind tunnel. Flow Measurement and Instrumentation, 72, 101717(1-6).

Hoseinzadeh, S., Ghasemiasl, R., Havaei, D. and Chamkha, A.J. (2018) Numerical investigation of rectangular thermal energy storage units with multiple phase change materials. Journal of Molecular Liquids, 271, 655-660.

Hoseinzadeh, S. and Heyns, P.S. (2020) Thermo-structural fatigue and lifetime analysis of a heat exchanger as a feedwater heater in power plant. Engineering Failure Analysis, 113, 104548(1-13).

Hoseinzadeh, S., Heyns, P.S., Chamkha, A.J. and Shirkhani, A. (2019) Thermal analysis of porous fins enclosure with the comparison of analytical and numerical methods. Journal of Thermal Analysis and Calorimetry, 138, 727-735.

Hoseinzadeh, S., Sahebi, S.A.R., Ghasemiasl, R. and Majidian, A.R. (2017) Experimental analysis to improving thermosyphon (TPCT) thermal efficiency using nanoparticles/based fluids (water). European Physical Journal Plus, 132, 197(1-8).

Jouhara, H., Almahmoud, S., Chauhan, A., Delpech, B., Bianchi, R., Tassou, S.A., G., Llera, Lago, F. and Arribas, J.J. (2017) Experimental and theoretical investigation of a flat heat pipe heat exchanger for waste heat recovery in the steel industry. Energy, 141, 1928-1939.

Jouhara, H. and Meskimmon, R. (2018) An investigation into the use of water as a working fluid in wraparound loop heat pipe heat exchanger for applications in energy efficient HVAC systems. Energy, 156, 597-605. 
Karimi, G. and Culham, J.R. (2004) Review and Assessment of Pulsating Heat Pipe Mechanism for High Heat Flux Electronic Cooling. in The $9^{\text {th }}$ Intersociety Conference on Thermal and Thermomechanical Phenomena in Electronic Systems, Las Vegas, NV, USA, 52-58.

Katpradit, T., Wongratanaphisan, T., Terdtoon, P., Kamonpet, P., Polchai, A. and Akbarzadeh, A. (2005) Correlation to predict heat transfer char-acteristics of a closed end oscillating heat pipe at critical state. Applied Thermal Engineering, 25(1415), 2138-2151.

Maezawa, S., Gi, K.Y., Minamisawa, A. and Akachi, H. (1996) Thermal performance of capillary tube thermosyphon. in Proceedings of the $9^{\text {th }}$ International Heat-Pipe Conference, USA, 791-795.

Mahdavi, M., Tiari, S., Schampheleire, S.D. and Qiu, S. (2018) Experimental study of the thermal characteristics of a heat pipe. Experimental Thermal and Fluid Science, 93, 292-304.

Mameli, M., Marengo, M. and Zinna, S. (2012) Thermal simulation of a pulsating heat pipe: effects of different liquid properties on a simple geometry. Heat Transfer Engineering, 33(14), 1177-1187.

Mozumder, A.K., Chowdhury, M.S.H. and Akon, A.F. (2011) Characteristics of Heat Transfer for Heat Pipe and Its Correlation. International Scholarly Research Network ISRN Mechanical Engineering, 5-6.

Parametthanuwat, T., Rittidech, S. and Pattiya, A. (2010) A correlation to predict heat-transfer rates of a two-phase closed thermosyphon (TPCT) using silver nanofluid at normal operating conditions. International Journal of Heat and Mass Transfer, 53, 4960-4965.

Peterson, G.P. (1988) Analytical development and computer modeling of a bellows-type heat pipe for the cooling of electronic components. Heat Transfer Engineering, vol. 9, no. 3, pp. 101-109.

Rittidech, S., Donmaung, A. and Kumsombut, K. (2009) Experimental study of the performance of a circular tube solar collector with closed-loop oscillating heat-pipe with check valve (CLOHP/CV). Renewable Energy, 34, 2234-2238.

Rittidech, S., Phalasin, K. (2005) Effect of geometry and dimensionless parameters on heat transfer characteristics of a closed-end oscillating heat pipe at vertical position. American Journal of Applied Sciences, 2(11), 1493-1498.
Rittidech, S., Terdtoon, P., Murakami, M., Kamonpet, P. and Jompakdee, W. (2003) Correlation to predict heat transfer characteristics of a closed-end oscillating heat pipe at normal operating condition. Applied Thermal Engineering, 23(4), 497-510.

Sasongko, S.B., Hadiyanto, H., Djaeni, M. and Perdanianti, A.M. (2020) Effects of drying temperature and relative humidity on the quality of dried onion slice. Heliyon, 6(7), e04338.

Shafii, M.B., Arabnejad, S., Saboohi, Y. and Jamshidi, H. (2010) Experimental investigation of pulsating heat pipes and a proposed correlation. Heat Transfer Engineering, 31(10), 854861.

Siriwan, N., Chompookham, T., Ding, Y. and Rittidech, S. (2017) Heat transfer predictions for helical oscillating heat pipe heat exchanger: transient condition. Journal of Mechanical Science and Technology, 31(7), 3553-3562.

Sriudom, Y., Rittidech, S. and Chompookham, T. (2014) The helical oscillating heat pipe: flow pattern behaviour study. Advances in Mechanical Engineering, 7(1), 1-11.

Thongdaeng, S., Pipatpaiboon, N. and Rittidech, S. (2014) Influence of void fraction and filling ratio on heat transfer characteristics of a packing bed thermosyphon (PBTP). KKU research journal, 19(1), 75-81.

Tiari, S., Qiu, S. and Mahdavi, M. (2015) Numerical study of finned heat pipe-assisted thermal energy storage system with high temperature phase change material. Energy Conversion and Management, 89, 833-842.

Tiari, S., Qiu, S. and Mahdavi, M. (2016) Discharging process of a finned heat pipe-assisted thermal energy storage system with high temperature phase change material. Energy Conversion and Management, 118, 426-437.

Yi, J., Liu, Z.H. and Wang, J. (2003) Heat transfer characteristics of the evaporator section using small helical coiled pipes in a looped heat pipe. Appleied Thermal Engineering, 23(1), 89-99.

Zhao, J., Rao, Z., Liu, C. and Li, Y. (2016) Experimental investigation on thermal performance of phase change material coupled with closed-loop oscillating heat pipe (PCM/CLOHP) used in thermal management. Applied Thermal Engineering, 93, 90-100.

Zhu, L. and Yu, J. (2016) Simulation of steady-state operation of an ejector-assisted loop heat pipe with a flat evaporator for application in electronic cooling. Applied Thermal Engineering, 95, 236-246. 